\title{
Justification of the methodological approach to formation of the parties of innovation activities in holdings
}

\author{
Inessa Lukmanova ${ }^{1}$,Evgeniya Sizova ${ }^{2,}$, Evgeniya Zhutaeva $^{2}$ and Olga Mironova ${ }^{3}$ \\ ${ }^{1}$ Moscow State University of Civil Engineering, Yaroslavskoe shosse, 26, Moscow, 129337, Russia \\ ${ }^{2}$ Voronezh State Technical University, Moscow Avenue, 14, Voronezh, 394026, Russia \\ ${ }^{3}$ Moscow Aviation Institute, Volokolamskoe highway, 4, Moscow, 125993, Russia
}

\begin{abstract}
The paper presents the problematic area of the formation of the parties of innovation activities in holdings and its methodological justification. The objective preconditions for differentiating intersubject interactions as a part of innovation activity with the participation of holdings are considered. Features of the formation of innovation strategies and goal-setting mechanisms are structured; their features in large enterprises are emphasized. The importance of determining the optimal parties of the innovation network as a factor of increasing the efficiency of implementation of innovation activity is substantiated. The external and internal environments of the holding are considered as sources of attracting participants of innovation activity. Features of the procedure for selecting the structure of innovation activity, complicated by the conditions of multiproject environment, are presented. Positive effects from the introduction of the scientific approach to the determination of the parties of innovation activity were revealed.
\end{abstract}

\section{Introduction}

Innovation activity should combine the rational organization of fundamental and applied scientific research and, first of all, be oriented to the maximum effective realizability within the real production. The use of innovation developments in the modern economy largely depends on the effective interaction between units and entities that carry out fundamental and applied scientific research, design and engineering development, manufacturing, and marketing research. In this regard, the issues of economics, organization and management of the interaction of innovative organizations that ensure the efficiency of innovation processes and, ultimately, strategic innovation development, are becoming one of the most relevant.

Innovation activity is characterized by a high level of risk, significant expenditure of financial and other resources, as well as complexity and duration, which requires simultaneous and mutually agreed participation in the implementation of innovation projects of a significant number of entities.

*Corresponding author: sizova@vgasu.vrn.ru 
In scientific works, attempts were repeatedly made to systematize the parties of innovation activity from the standpoint of identifying similar features and functions in the innovation process, the role played, and the innovation potential. [1-5] Among the common disadvantages of the proposed classifications, it is possible to identify an excessive level of detail, based on the insignificant differentiation of subjects, and, conversely, too broad consideration of subjects that do not allow obtaining sufficiently accurate and reliable results. Besides, insufficient attention is paid to participation of holding companies in innovation activities, which is of particular importance, since large business, as a rule, is recognized as one of the most innovatively active market participants. Among the characteristics of large enterprises that allow them to form competitive advantages, it is possible to emphasize stability under the influence of destructive factors of the external environment, extensive opportunities for diversification of activity, preferences in attracting funds from the state and credit institutions, the effect of the scale of production, and a significant concentration of material, labor and other resources. [6-9] However, the issues of the operation of large enterprises in the innovation environment, their role and the mechanisms of innovation activity have not been adequately reflected in scientific research. At the same time, it is necessary to take into account that the innovation activity of the holding is further complicated by the fact that, being essentially a set of economic units characterized by considerable independence, it acts as a single entity. As a consequence, it is important to consider the processes of formation of the structure of innovation activity in large business associations.

\section{Materials and Methods}

Management of innovations in holdings allows solving a number of problems aimed at increasing their efficiency and performance. At the same time, the range of problems to be solved is largely determined by the membership of innovation activity. Therefore, the process of analyzing the formation of the parties of innovation activity precedes the identification of its characteristics, which will determine the membership and the nature of the relationship between participants, sources and procedure for financing, methods of managing the innovation process, and a number of other characteristics.

Innovation activity of large enterprises is represented by a complex of innovations of various types, which, first of all, should be taken into account in the strategy. If innovations are implemented as an instrument of adaptation to environmental change or crisis management, this aspect should also be taken into account in the tactics of managing innovation activity. Since innovations are a powerful tool for influencing a company's state, its status and relations with other market players, before setting the goals of innovation, it is necessary to analyze the previous experience of achieving the goals, objectives and priorities, the current position of the organization, its strengths and weaknesses, and also the available tools, technology, and organizational and managerial potential. It is also necessary to try to predict the potential market change, the changing needs of consumers and take into account the difference in the timing of achieving the goals, since most of the goals of innovation can be achieved only over a long period of time. As a rule, the goals of innovation activity correlate with the goals of the strategy of activity or tactics.

The goal setting procedures in innovation activity have a fundamental difference from other directions, since, on the one hand, the implementation of innovation has an unambiguous, certain and achievable goal. On the other hand, based on the multistage nature, uniqueness and non-reproducibility of the activities carried out, there is a need for regular implementation of goal adjustments by all involved participants according to the results of each stage of the innovation process. For each business unit and subsidiary, it is necessary to take into account a lot of factors, take into consideration the multitasking 
strategy of each division and form the tree of the goals of all business units, taking into account the development mission of the holding. However, the algorithm for building a strategy unique for each business unit, and the corresponding mission of the holding as a whole is identical at each level. A high level of coordination of the participating subjects and the efficiency of their interaction under the given conditions can be achieved only if the goal setting is correct, which, in this case, must ensure the unity of the common goal while respecting the interests of each of the subjects, as well as the reality of its achievement within the planning horizon.

When determining the parties of the holding's innovation activity, it is of particular importance to take into account the specifics of the holding as an integrated structure. Despite the fact that the holding represents the unification of some finite number of enterprises, it acts as a single entity. Accordingly, the categories "external environment" and "internal environment" are applicable to the holding company. The parent organization, subsidiaries and affiliated structures, branches, subdivisions that are part of the holding are subjects of the internal environment, and other entities that are not part of the holding and function independently are the subjects of the external environment. Features of subject interaction within the innovation activity will be different depending on whether external subjects will be involved in it and what functions and tasks will be delegated to them.

Based on the above, it can be concluded that the choice of the parties of innovation activity is an important aspect that allows forming an innovation network that meets the requirements of a particular project. The innovation network is characterized by a complex set of interactions, complicated by possible contradictions in the interests of the subjects, as well as by the individual features of the internal environment of the networked organizations, which leads to the formation of interaction risks. The structuring of innovation activity of the holding company must take into account the features of selecting the optimal membership from the standpoint of the features of innovation activity as a complex, multistage, high-risk activity for creating innovation.

\section{Results}

Innovation projects are the starting elements of innovation activity and in general terms represent the organizational framework for the implementation of an innovation process balanced, systematic, based on the methodology for obtaining knowledge, ideas and the final result. [10] For an economic entity, the result of implementing innovation will directly depend on the characteristics of the selected project. The project itself, even with a rational organization of innovation activity, can be not only inefficient, but also lead to negative consequences (both financial and other), since innovation activity affects all aspects of the economic activities of enterprises.

However, even with the optimal choice of the project to implement, the efficiency of its implementation will largely be determined by the parties of the innovation activity. Since innovation resources are distributed asymmetrically between the subjects, they have to carry out joint activity to implement an innovation project, achieving such a composition and building intersubject relations in such a way as, on the one hand, to fully meet the requirements of the project for its successful implementation, and on the other hand - to ensure satisfaction of the requirements of the subjects to achieve a sufficient level of profitability from their participation in the network. Taking into account the complexity and diversity of innovation activity and the need to ensure sustainable development, it is necessary to determine the parties of innovation activity as a set of participants involved in the implementation of the innovation process and having a direct impact on the creation of innovation or promoting its introduction, development or spreading. 
The variety of types of innovation projects generates a variety of economic ties between their participants not limited to a single concept. It should be noted that innovation activity is carried out by subjects of various sectors of science with different goals, functions, approach to the implementation of innovation activity, and sources of funding.

As it was already mentioned, the external environment of the holding is not only a factor that generates forces influencing the efficiency of innovation activity, but also serves as a source of opportunities for expanding scientific and production ties and gaining experience in innovative interaction with entities that are not part of the holding. Special attention should be paid to the analysis of the external environment, since it is the external environment that determines the management decisions that help the company to function best in it. Without taking into account the factors of the external environment at each particular moment of time, it is impossible to guarantee the optimality of the membership of innovation activity. When studying the factors of the environment of the holding, it is not so much the values of the indicators (factors) that are of interest, but how they affect innovation activity.

Along with the analysis of the external environment, in order to develop an innovation strategy, it is advisable to analyze the internal environment. This process is proposed to be carried out in two directions: a primary analysis based on the features of innovation activity, which are characteristic of a group of enterprises united by common features, and also an in-depth analysis that identifies the individual features of the particular enterprise under consideration (Fig. 1).

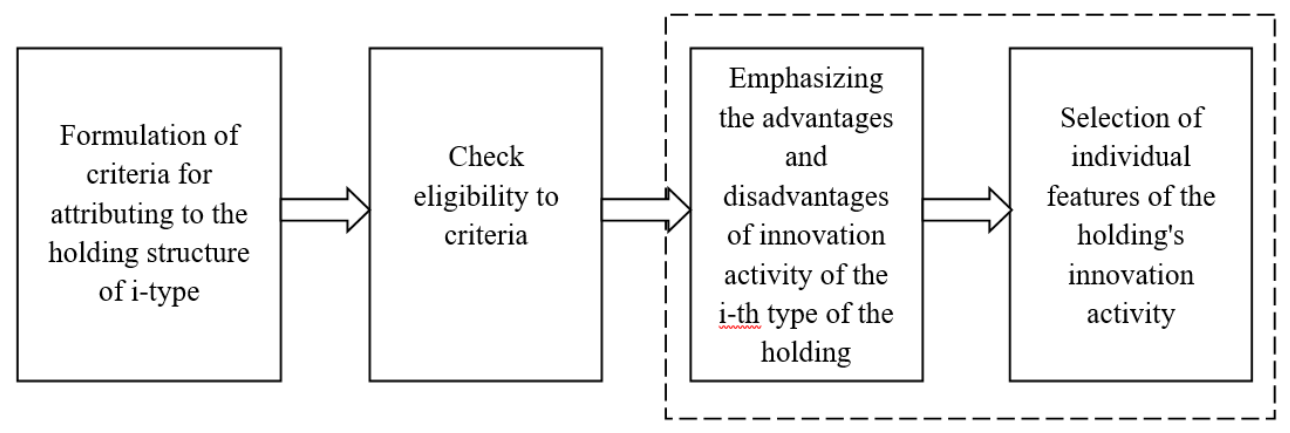

Fig. 1. The process of determining the advantages and disadvantages of the holding.

The same subject can be part of the innovation network for several ongoing projects simultaneously. This may concern both the internal subjects of the holding engaged in innovation activity and external ones. This will be facilitated by the existence of partnerships and cooperation agreements with other enterprises, research institutes, universities, and other entities, ensuring not one-time but regular interaction in the field of innovation activity.

Thus, the same subject can simultaneously be a participant of several innovation projects. The composition of internal subjects should be determined based on the needs and functions performed. However, involving the same subject in the process of implementing a large number of projects may lead to a decrease in the efficiency of its work, deterioration in the quality of work or failure to meet the planned deadlines for their implementation due to excessive workload and dispersion of resources. The subjects external to the holding are responsible for the performance of work in accordance with contracts or other relevant documents and, therefore, independently assess their ability and willingness to participate in a particular project.

The set of subjects of the holding's innovation activity under the conditions of multiproject environment is shown schematically in fig. 2 . 


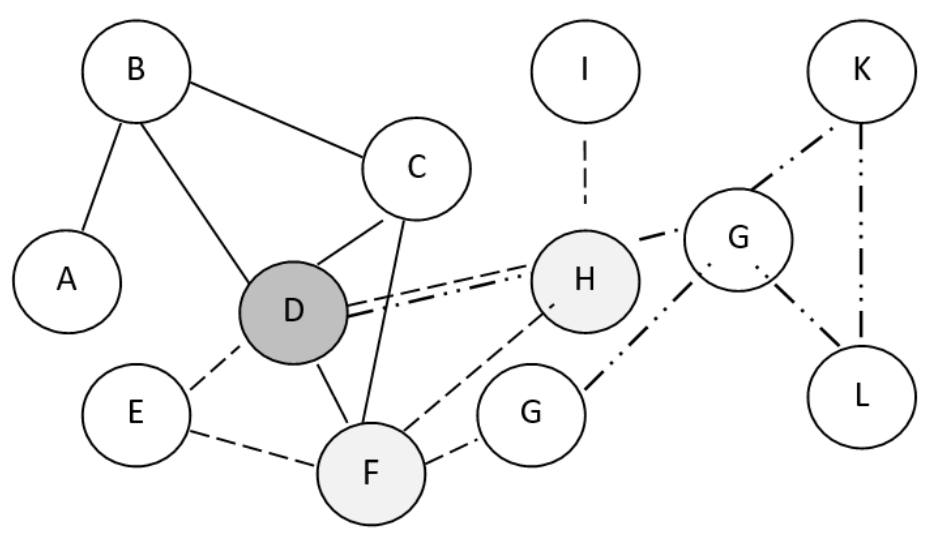

- innovation network of project 1

$---\quad$ - innovation network of project 2

$-\cdots-\quad$ innovation network of project 3

- occupancy rate of the subject in innovation networks of different projects

Fig. 2. Set of subjects of the holding's innovation activity under the conditions of multi-project environment.

Consequently, multi-project environment is a factor that hinders the process of managing innovation activity of the holding and imposes special requirements to the processes of forming the structure of innovation activity. Determining the degree of dependence of work performed in various projects, their level of "adaptability" and priority is an important aspect of innovation management. An equally important aspect is the choice of project selection criteria, which allow simultaneously evaluating the project comprehensively, maintain a certain level of materiality (prioritization) of criteria, and most importantly, ensure high speed and accuracy of project analysis procedures.

Scientific approach to formation of the parties of innovation activity, taking into account the above factors and characteristics, will allow achieving the following advantages when implementing the innovation process:

- ensuring the safety and balance of the internal environment of the holding due to the careful selection and analysis of subjects for interaction;

- improving the quality of fulfillment of obligations under the innovation process by an external subject as a result of reducing the likelihood of opportunistic behavior;

- increasing the efficiency of the communication system both within the holding and with the subjects of the external environment, which will minimize the possibility of incompleteness, untimely receipt, corruption, misinterpretation of information and the possibility of its leakage;

- using the accumulated knowledge base, unique equipment, highly qualified personnel of the external subject in the absence of their own capabilities;

- reducing the risks of default on obligations by the external subject as a result of unforeseen factors (loss of solvency, eligibility, etc.);

- focusing efforts and resources on those operations that are effectively carried out by the holding's own forces, and those that are strategically advisable to keep under its control;

- reducing the possibility of errors arising from the complexity of the mechanisms for intersubject transfer of intellectual property (completed/unfinished innovations), the 
possibility of error in the implementation/execution of transactions, the imperfection of assessment mechanisms, etc.

According to [11], the parties and nature of the interaction, taking into account the above directions, should be determined taking into account the following factors and conditions:

- conditions for the emergence and development of subjects of innovation activity;

- the degree of diversification of business processes and phases of the innovation cycle, the order of their redistribution;

- the composition and structure of the innovation potential of all prospective subjects;

- the level of competition in the industry, the type and structure of the industry market.

\section{Discussions}

Creating a mechanism for the interaction of subjects in order to promote high-tech products on the domestic and foreign markets, contributing to the achievement of maximum efficiency in the implementation of innovation projects through the implementation of a set of concerted and coordinated actions, is an extremely important task. [12]

Innovative intersubject interaction is specific, arising from the features of the innovation process itself and different from typical relations regarding the sale and purchase of goods, works, services. These features are aggravated by the presence of a complex system of relations within the holding itself. Consequently, it requires the allocation of specific risks of the holding's innovation process with the involvement of subjects of external environment.

Due to the complexity and other features of the parties of innovation relations, it follows that civil law pertaining to the intellectual property institute, as well as the law of obligations that mediate the circulation of property and non-property rights, and norms of contractual structures on the procedure for experimental design and research work is not enough. The implementation of the model of inter-company interaction requires a revision of existing ideas about management related to the level of the method and control, protection of intellectual property, training and integration. Inter-company interaction, in turn, allows economic agents to maintain a balance between self-organizing and controlled behavior, combining innovative diversity and freedom of activity with necessary level of integration.

\section{Conclusion}

Innovation management is a complex process that does not involve the use of "template" methods of management due to the features inherent to innovation. The choice of the innovation management structure in the holding will have a significant impact on the efficiency of innovation activity. Structures are distinguished by the degree of centralization and directivity, the direction of the totality of flows arising in the course of innovation activity, as well as the nature of interaction between divisions, subsidiary (dependent) companies and external subjects.

The scientific approach to the choice of the parties of innovation activity is the most important aspect that allows formation of the innovation network that meets the requirements of a specific project. The innovation network is characterized by a complex set of interactions between the subjects, complicated by possible contradictions in the interests of the subjects, as well as individual features of the internal environment of the organizations participating in the network, which leads to the formation of interaction risks. The process of structuring innovation activity of a large holding company must take into 
account the specifics of selecting the optimal membership from the standpoint of the specifics of innovation activity as a complex, multi-stage, high-risk activity for creating innovation.

\section{References}

1. E. Sizova, E. Zhutaeva, R. Gorshkov, V. Smirnov, E.Kochetkova, MATEC Web of Conferences 170, 01126 (2018)

2. K. Gumba, S. Belyaeva, IOP Conference Series: Earth and Environmental Science 90(1), 012163 (2017)

3. K. Zhiharev Russian Economic Online Journal 2, 33-45 (2011)

4. L. Obolenskaya Innovation Management 4, 55-61 (2014)

5. A. Bukreev, O. Vasilyeva, V. Vlasenko, E. Sizova, MATEC Web of Conferences 106, 08034 (2017)

6. S. Uvarova, S. Belyaeva, L. Myshovskaya, IOP Conference Series: Earth and Environmental Science 90(1), 012169 (2017)

7. K. Gumba, S. Uvarova, S. Belyaeva, S. Revunova, MATEC Web of Conferences 106, 08023 (2017)

8. E. Sizova, E. Zhutaeva A. Chugunov, MATEC Web of Conferences 33, 03016 (2018)

9. S. Uvarova, V. Vlasenko, A. Bukreev, L. Myshovskaya, O. Kuzina, E3S Web of Conferences 33, 03022 (2018)

10. T. Drock Young Scientist 10(2), 60-64 (2015)

11. M. Borovskaya, I. Shchevchenko, Russian Economic Online Journal 4, 76-82 (2010)

12. T. Morozova, News of the Southern Federal University. Technical science 1(78), 146150 (2008) 